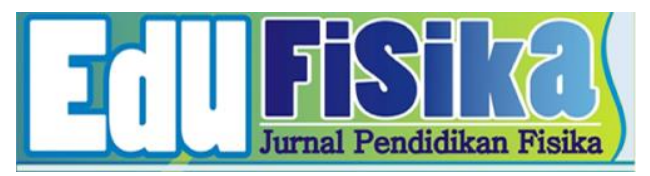

\title{
HUBUNGAN ANTARA MINAT BELAJAR DAN MOTIVASI BELAJAR TERHADAP HASIL BELAJAR FISIKA SISWA KELAS X SMA
}

Angela Anastasia Taa ${ }^{1}$, An Nisaa Al Mumin Liu ${ }^{2}$, Melyanus Kaleka ${ }^{3}$

Pendidikan Fisika Universitas Flores, Nusa Tenggara Timur, Indonesia

Coressponding author email : angelataa56@yahoo.com

\section{Info Artikel}

Diterima:

23 Desember 2020

Disetujui:

31 Mei 2021

Dipublikasikan:

30 Juni 2021

\begin{abstract}
Abstrak:
Penelitian ini bertujuan untuk mengetahui hubungan antara minat belajar dan motivasi belajar terhadap hasil belajar fisika. Jenis penelitian yang digunakan adalah penelitian korelasional dengan pendekatan kuantitatif. Populasi dalam penelitian ini adalah siswa kelas X IPA SMA Negeri 1 Wewewa Selatan tahun ajaran 2019/2020. Pada penelitian ini pengambilan sampel dilakukan dengan teknik random sampling yang diambil sebanyak 35 siswa. Teknik pengumpulan data dilakukan melalui angket dan dokumentasi. Data dianalisis menggunakan uji korelasi pearson product moment. Hasil menunjukkan bahwa terdapat hubungan yang signifikan antara minat belajar dan hasil belajar fisika. Hasil analisis diperoleh nilai signifikansinya $0,000<0,05$. Motivasi belajar dan hasil belajar fisika juga menunjukkan bahwa terdapat hubungan yang signifikan. Hasil analisis diperoleh nilai signifikansinya $0,001<0,05$.
\end{abstract}

Kata kunci: Minat belajar, motivasi belajar dan hasil belajar

\begin{abstract}
:
This study aims to determine the relationship between learning interest and learning motivation on physics learning outcomes. The type of research used is correlational research with a quantitative approach. The population in this study were students of class $X$ science at SMA Negeri 1 Wewewa Selatan in the 2019/2020 academic year. In this study, the sample was taken using a random sampling technique taken as many as 35 students. Data collection techniques were carried out through questionnaires and documentation. The data were analyzed using the Pearson product moment correlation test. The results show that there is a significant relationship between interest in learning and learning outcomes in physics. The results of the analysis obtained a significance value of $0.000<0.05$. Learning motivation and physics learning outcomes also show that there is a significant relationship. The results of the analysis obtained a significance value of $0.001<0.05$.
\end{abstract}

Keywords: Interestting in learning, motivation, learning outcomes

Copyright @ 2021 Edufisika: Jurnal Pendidikan Fisika 


\section{Pendahuluan}

Pada umumnya pendidikan merupakan salah satu kegiatan universal dalam kehidupan manusia. Pendidikan juga dipandang sebagai kegiatan memanusiakan manusia. Proses pendidikan berada dan berkembang bersama perkembangan hidup dan kehidupan manusia, bahkan kedua-duanya adalah proses yang satu.

Perkembangan yang terjadi pada lingkungan sekitar amat cepat dalam berbagai aspek kehidupan, terutama kemajuan pada bidang ilmu dan teknologi. Seiring dengan perkembangan tersebut, maka akan menimbukan berbagai tantangan terutama bagi penduduk bumi ini agar dapat sepadan dengan tuntutan perkembangan tersebut. Agar dapat mencapai tujuan pendidikan nasional yakni meningkatkan ketaqwaan kepada Tuhan Yang Maha Esa, kecerdasan dan keterampilan maka salah satu cara yang dapat dilakukan adalah dengan menumbuhkan kemandirian belajar pada setiap warga negara khususnya pada siswa di berbagai sekolah.

Pendidikan adalah sebuah proses yang dilakukan untuk membentuk kepribadian manusia. Pada umumnya, pendidikan dilakukan untuk membentuk manusia yang bermoral serta berilmu. Berbicara tentang masalah yang terjadi pada pendidikan, maka berkaitan pula dengan masalah tentang lingkungan pendidikan. Lingkungan pendidikan yakni lingkungan keluarga, lingkungan sekolah dan masyarakat atau dikenal dengan tripusat pendidikan.Untuk mencapai tujuan pendidikan yang diharapkan maka tidak lepas dari peranan seorang guru di sekolah yakni bagaimana cara seorang guru dalam menumbuhkan minat serta motivasi belajar di sekolah. Untuk itu perlu dilakukan usaha yang optimal agar tujuan yang diharapkan dapat tercapai.

Minat pada dasarnya adalah penerimaan akan suatu hubungan antara diri sendiri dengan sesuatu diluar diri. Semakin kuat atau dekat hubungan tersebut, semakin besar minat (Slameto, 2010). Minat adalah suatu kondisi yang terjadi apabila seseorang melihat ciri-ciri atau arti sementara situasi yang dihubungkan dengan keinginan-keinginan atau kebutuhan sendiri (A.M, 2016). Minat adalah suatu kesukaan, kegemaran atau kesenangan akan sesuatu (Susanto, 2016).

Motivasi merupakan kekuatan baik dari dalam maupun dari luar yang mendorong seseorang untuk mencapai tujuan tertentu yang telah ditetapkan sebelumnya (Uno, 2016). Motivasi belajar merupakan keseluruhan daya penggerak dalam diri siswa yang menimbulkan kegiatan belajar, yang menjamin kelangsungan dari kegiatan belajar dan yang memberikan arah pada kegiatan belajar, sehingga tujuan yang hendak dicapai oleh subjek belajar dapat tercapai dengan baik (A.M, 2016). Motivasi belajar yaitu salah satu dorongan yang memiliki peranan penting dalam memberikan gairah atau semangat dalam belajar, sehingga anak yang bermotivasi kuat akan memiki energi yang untuk melakukan kegiatan belajar dengan baik (Syarif, 2016).

Hasil belajar merupakan kemampuan-kemampuan yang dimiliki siswa setelah mereka menerima pengalaman belajarnya (Sudjana, 2009). Guru diharapkan melaksanakan hasil penilaian secara berkesinambungan. Salah satu tujuan dari penilaian hasil belajar adalah untuk mengetahui sejauh mana siswa telah mencapai hasil belajar yang telah direncanakan sebelumnya (Majid, 2011). Hasil belajar adalah sejumlah pengalaman yang diperoleh siswa yang mencakup ranah kognitif, afektif dan psikomotorik. Belajar tidak hanya penguasaan konsep teori mata pelajaran saja, tapi juga penguasaan kebiasaan, persepsi, kesenangan, minat-bakat, penyesuaian sosial, macam-macam keterampilan, cita-cita, keinginan, dan harapan. Belajar merupakan proses yang kompleks dan terjadinya perubahan perilaku pada saat proses belajar di amati pada perubahan perilaku siswa setelah melakukan penilaian (Rusman, 2012). Hasil belajar merupakan kemampuan-kemampuan yang dimiliki siswa setelah mereka menerima pengalaman belajarnya. Dalam sistem pendidikan nasional rumusan tujuan pendidikan, baik tujuan kurikuler, maupun tujuan instruksional (Sudjana, 2009).

Hasil pra penelitian yang dilakukan dengan menggunakan wawancara langsung pada guru fisika di SMA Negeri 1 Wewewa Selatan, menyatakan bahwa dalam proses pembelajaran di sekolah pada mata pelajaran fisika hingga saat ini belum memberikan hasil yang memuaskan. Hal ini terjadi karena siswa 
cenderung diam dan tidak menjawab pertanyaan-pertanyaan yang diajukan oleh guru sehingga belum menunjukan bahwa siswa memiliki minat dan motivasi dalam mempelajari fisika. Data hasil belajar dilihat dari nilai ujian semester siswa pada tahun sebelumnya menunjukan bahwa masih banyak siswa yang belum mencapai KKM yaitu sebanyak $65,1 \%$. Hasil belajar pada siswa SMA Negeri 1 Wewewa Selatan saat ini masih rendah. Berdasarkan uraian di atas, maka tujuan penelitian ini menganalisis hubungan antara minat belajar dan motivasi belajar terhadap hasil belajar fisika siswa kelas X SMA Negeri 1 Wewewa Selatan.

\section{Metode Penelitian}

Penelitian ini dilaksanakan di SMA Negeri 1 Wewewa Selatan, tepatnya di Desa Tena Teke, Kecamatan Wewewa Selatan, Kabupaten Sumba Barat Daya, Nusa Tenggara Timur. Penelitian ini dilakukan mulai dari tanggal 16 juni sampai dengan 30 juni 2020. Populasi dalam penelitian ini adalah siswa kelas X IPA di SMA Negeri 1 Wewewa Selatan yang terdiri dari 3 kelas yang berjumlah 95 siswa. Ketiga kelas tersebut yaitu X IPA ${ }^{1}, \mathrm{X} \mathrm{IPA}^{2}$ dan X IPA ${ }^{3}$. Sampel dalam penelitian ini adalah siswa kelas $\mathrm{X}$ IPA $^{1}$ yang berjumlah 35 orang.

Jenis Penelitian yang digunakan dalam penelitian ini adalah Korelasional. Menurut Hasan (2002) Metode Korelasional merupakan metode yang digunakan untuk mencari hubungan di antara variabelvariabel yang di teliti. Tujuan metode Korelasional yaitu untuk meneliti sejauh mana variabel pada satu vektor yang berkaitan dengan variasi pada vektor lainnya. Pada penelitian ini mengggunakan pendekatan kuantitatif. Pendekatan kuantitatif digunakan untuk mengukur semua variabel bebas dan terikat dengan menggunakan angka-angka yang diolah melalui analisis statistik. Desain penelitiannya ditunjukkan pada gambar 1 sebagai berikut.

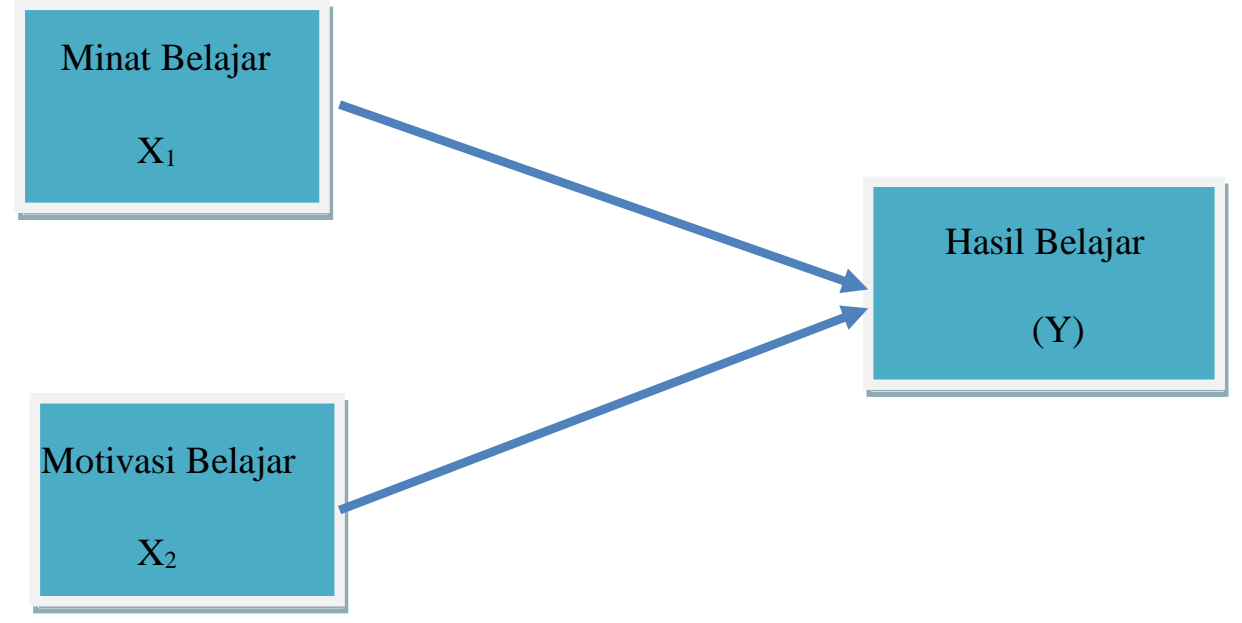

Gambar 1. Desain Penelitian

Teknik pengumpulan data merupakan cara seseorang peneliti untuk mengumpulkan data yang diperlukan dalam penelitian. Teknik pengumpulan data dalam penelitian ini menggunakan metode kuesioner (angket) dan dokumentasi nilai ujian akhir semester (UAS). Metode angket digunakan untuk mengambil data variabel bebas yaitu minat belajar dan motivasi belajar. Dokumentasi digunakan dalam penelitian ini untuk memperoleh data hasil belajar.

Instrumen penelitian merupakan alat untuk menjaring data. Instrumen yang digunakan dalam penelitian ini berdasarkan konsep dasar teori-teori dan variabel-variabel penelitian. Langkah-langkah ini dilakukan untuk mencerminkan tentang variabel yang ingin diteliti. Angket yang dimaksudkan adalah berupa pernyataan- pernyataan yang dapat diisi oleh responden sesuai dengan perintah yang tertera. 
Dengan pertanyaan tersebut diharapkan dapat mengumpulkan informasi atau data yang diperlukan dalam penelitian yaitu minat belajar dan motivasi belajar. Questioner tersebut berisi keterangan mengenai minat belajar dan motivasi belajar pada SMA Negeri 1 Wewewa Selatan. Berikut adalah kisi-kisi instrumen pada tabel 1 minat belajar dan tabel 2 motivasi belajar.

Tabel 1. Kisi-kisi instrumen Minat Belajar

\begin{tabular}{|c|c|c|c|c|}
\hline \multirow[t]{2}{*}{ Indikator } & \multirow[t]{2}{*}{ Keterangan } & \multicolumn{2}{|c|}{ Pernyataan } & \multirow{2}{*}{$\begin{array}{c}\text { Jumlah } \\
\text { Item }\end{array}$} \\
\hline & & Positif & Negatif & \\
\hline \multirow{3}{*}{ Perasaan senang } & Pendapat siswa tentang pembelajaran fisika & & & \\
\hline & Kesan siswa terhadap guru fisika & $3,4,5$ & $1,2,6$ & 6 \\
\hline & $\begin{array}{l}\text { Perasaan siswa selama mengikuti pembelajaran } \\
\text { fisika }\end{array}$ & & & \\
\hline \multirow{4}{*}{ Perhatian } & Perhatian saat mengikuti pembelajaran fisika & $8,10,11,14$ & & \\
\hline & Perhatian siswa saat diskusi pelajaran fisika & & $7,9,12,13$ & 9 \\
\hline & & &, 15 & \\
\hline & $\begin{array}{l}\text { Rasa ingin tahu siswasaat mengikuti pelajaran } \\
\text { fisika }\end{array}$ & & & \\
\hline \multirow[t]{2}{*}{ Ketertarikan } & Penerimaan siswa saat diberi tugas/PR oleh guru & $\begin{array}{l}16,17,20 \\
21,22\end{array}$ & 18,19 & 7 \\
\hline & Kesadaran tentang belajar dirumah & & & \\
\hline \multirow[t]{2}{*}{ Keterlibatan siswa } & Kegiatan siswa setelah masuk sekolah & 23 & 24 & 2 \\
\hline & Jumlah keseluruhan & & & 24 \\
\hline
\end{tabular}

Tabel 2. Kisi-kisi instrumen Motivasi Belajar

\begin{tabular}{lrrr}
\hline \multirow{2}{*}{ Indikator } & \multicolumn{2}{c}{ Pertanyaan } & Jumlah \\
\cline { 2 - 3 } Adanya hasrat dan keinginan berhasil & $1,2,3$ & 4 & 4 \\
\hline Adanya dorongan dan kebutuhan dalam belajar & 5,7 & 6,8 & 4 \\
Adanya harapan dan cita-cita masa depan & $9,10,11$ & 12 & 4 \\
Ingin mendalami bidang fisika & 13,14 & 15 & 3 \\
Senang pada kegiatan menarik & 16,17 & 18 & 3 \\
Tekad yang kuat dalam diri siswa untuk berhasil & 19,21 & 20 & 3 \\
Senang bekerja sendiri & & & 4 \\
Jumlah keseluruhan & 22,23 & 24,25 & 4 \\
\hline
\end{tabular}


Dalam penelitian ini data-data yang sudah diperoleh kemudian di lakukan analisis. Analisis data bertujuan untuk memperoleh data ke dalam data yang lebih sederhana dan bentuknya dapat lebih mudah dimengerti sehingga data tersebut digunakan sebagai dasar untuk menjawab masalah yang sudah dirumuskan. Di mana teknik analisis data digunakan dalam menganalisis data untuk menguji hipotesis yang diajukan. Tujuan analisis ini yaitu untuk mengetahui apakah ada pengaruh dan hubungan antara variabel $\mathrm{X}$ terhadap variabel $\mathrm{Y}$ dalam menggambarkan hasil penelitian angka. Uji selengkapnya dilakukan dengan menggunakan software SPSS version 24.

\section{Hasil dan pembahasan}

Data hasil penelitian terdiri dari variabel bebas yaitu variabel minat belajar dan motivasi belajar serta variabel terikatnya hasil belajar fisika dari nilai ujian semester 1 siswa pada kelas X IPA ${ }^{1}$ SMA Negeri 1 Wewewa Selatan tahun ajaran 2019/2020. Dan dapat di lihat ringkasan data analisis deskriptif pada tabel 1 minat belajar, tabel 4 motivasi belajar dan tabel 5 hasil belajar.

Tabel 3. Data Deskripsi Minat Belajar

\begin{tabular}{|c|c|c|}
\hline \multirow[t]{2}{*}{$\mathrm{N}$} & Valid & 35 \\
\hline & Missing & 0 \\
\hline & & 56,86 \\
\hline \multicolumn{2}{|c|}{ Median } & 55,00 \\
\hline \multicolumn{2}{|c|}{ Std. Deviation } & 9,858 \\
\hline \multicolumn{2}{|c|}{ Variance } & 97,185 \\
\hline \multicolumn{2}{|c|}{ Minimum } & 40 \\
\hline \multicolumn{2}{|c|}{ Maximum } & 75 \\
\hline
\end{tabular}

Berdasarkan tabel 3 di atas, jumlah siswa yang mengisi angket 35 orang, diperoleh nilai rata-rata (mean) sebesar 56,86, titik tengah (median) sebesar 55,00, nilai minimum sebesar 40 dan maksimum sebesar 75 .

Tabel 4. Data Deskripsi Motivasi Belajar

\begin{tabular}{lr}
\hline N & Valid \\
\cline { 2 - 3 } \multicolumn{1}{c}{ Missing } & 35 \\
\hline Mean & 58,57 \\
\hline Median & 59,00 \\
\hline Std. Deviation & 6,260 \\
\hline Variance & 39,193 \\
\hline Minimum & 44 \\
\hline Maximum & 73 \\
\hline
\end{tabular}


Berdasarkan tabel 4 di atas, jumlah siswa yang mengisi angket 35 orang, diperoleh nilai rata-rata (mean) sebesar 58,57, titik tengah (median) sebesar 59,00, nilai minimum sebesar 44 dan maksimum sebesar 73.

Tabel 5. Data Deskripsi Hasil Belajar

\begin{tabular}{lr}
\hline N $\quad$ Valid & 35 \\
\cline { 2 - 3 } \multicolumn{1}{c}{ Missing } & 0 \\
\hline Mean & 67,03 \\
\hline Median & 67,00 \\
\hline Std. Deviation & 1,706 \\
\hline Variance & 2,911 \\
\hline Minimum & 64 \\
\hline Maximum & 70 \\
\hline
\end{tabular}

Berdasarkan tabel 5 di atas, jumlah siswa yang mengisi angket 35 orang, diperoleh nilai rata-rata (mean) sebesar 67,03 titik tengah (median) sebesar 67,00 nilai minimum sebesar 64 dan maksimum sebesar 70 .

1. Uji Normalitas

a. Data Minat Belajar

Pada data minat belajar hasil pengujian statistik untuk teknik Kolmogorov-Sirmov dapat dilihat pada Tabel 6.

Tabel 6. Tests of Normality

\begin{tabular}{lr|r|r|rrrr}
\hline & \multicolumn{3}{c}{ Kolmogorov-Smirnov $^{\mathrm{a}}$} & \multicolumn{3}{c}{ Shapiro-Wilk } \\
\cline { 2 - 8 } & Statistic & Df & \multicolumn{1}{c}{ Sig. } & Statistic & df & \multicolumn{1}{c}{ Sig. } \\
\hline Minat Belajar &, 118 & & 35 &, $200^{*}$ &, 957 & 35 &, 190 \\
\hline
\end{tabular}

*. This is a lower bound of the true significance.

a. Lilliefors Significance Correction

Dengan menggunakan teknik Kolmogorov-Smirnov dapat dilihat untuk pengujian normalitasdiperoleh besarnya 0,118 dengan bilangan signifikan besarnya 0,200 dengan Taraf signifikan $\alpha=0,05$, jadi 0,200 >0,05 maka dapat disimpulkan bahwa data sampel minat belajar berdistribusi normal.

b. Data Motivasi Belajar

Pada data motivasi belajar hasil pengujian statistik untuk teknik Kolmogorov-Sirmov dapat dilihat pada Tabel 7.

Tabel 7. Tests of Normality

\begin{tabular}{|c|c|c|c|c|c|c|}
\hline & \multicolumn{3}{|c|}{ Kolmogorov-Smirnov ${ }^{\mathrm{a}}$} & \multicolumn{3}{|c|}{ Shapiro-Wilk } \\
\hline & Statistic & Df & Sig. & Statistic & $\mathrm{df}$ & Sig. \\
\hline Motivasi Belajar & ,121 & 35 & ,200* & ,983 & 35 & ,848 \\
\hline
\end{tabular}

*. This is a lower bound of the true significance.

a. Lilliefors Significance Correction

Hubungan Antata Minat... (Angela Anastasia Taa, dkk) hal:41-51 
Dengan menggunakan teknik Kolmogorov-Smirnov dapat dilihat nilai signifikansi besarnya 0,200 dengan Taraf signifikan $\alpha=0,05$, jadi 0,200 >0,05 maka dapat di simpulkan bahwa data sampel motivasi belajar berdistribusi normal.

c. Data Hasil Belajar Fisika

Pada data Hasil belajar fisika, hasil pengujian statistik menggunakan teknik KolmogorovSmirnovdapat dilihat pada Tabel 8.

Tabel 8. Tests of Normality

\begin{tabular}{|c|c|c|c|c|c|c|}
\hline & \multicolumn{3}{|c|}{ Kolmogorov-Smirnov ${ }^{\mathrm{a}}$} & \multicolumn{3}{|c|}{ Shapiro-Wilk } \\
\hline & Statistic & df & Sig. & Statistic & df & Sig. \\
\hline Hasil Belajar & ,122 & 35 & ,200* & ,952 & 35 & ,133 \\
\hline
\end{tabular}

*. This is a lower bound of the true significance.

a. Lilliefors Significance Correction

Dengan menggunakan teknik Kolmogorov-Smirnov dapat dilihat nilai signifikansi besarnya 0,200 dengan Taraf signifikan $\alpha=0,05$, jadi 0,200 > 0,05 maka dapat di simpulkan bahwa data sampel hasil belajar berdistribusi normal.

2. Uji Linearitas

a. Minat belajar dengan Hasil belajar fisika

Pada hasil pengujian statistik dapat dilihat uji linearitas regresi adalah pada bagian Deviation from Linearity.

Tabel 9. Uji Linieritas Minat dan Hasil Belajar

\begin{tabular}{|c|c|c|c|c|c|c|c|}
\hline & & & $\begin{array}{l}\text { Sum of } \\
\text { Squares }\end{array}$ & Df & $\begin{array}{l}\text { Mean } \\
\text { Square }\end{array}$ & $\mathrm{F}$ & Sig. \\
\hline \multirow{5}{*}{$\begin{array}{l}\text { Hasil Belajar * } \\
\text { Minat Belajar }\end{array}$} & \multirow{3}{*}{$\begin{array}{l}\text { Between } \\
\text { Groups }\end{array}$} & (Combined) & 49,471 & 7 & 7,067 & 3,855 &, 005 \\
\hline & & Linearity & 36,681 & 1 & 36,681 & 20,008 & ,000 \\
\hline & & $\begin{array}{l}\text { Deviation from } \\
\text { Linearity }\end{array}$ & 12,791 & 6 & 2,132 & 1,163 &, 355 \\
\hline & \multicolumn{2}{|c|}{ Within Groups } & 49,500 & 27 & 1,833 & & \\
\hline & \multicolumn{2}{|l|}{ Total } & 98,971 & 34 & & & \\
\hline
\end{tabular}

Berdasarkan tabel 4.7 di atas, diperoleh nilai signifikansisebesar 0,355 dengan taraf signifikansi $\alpha=0,05$, jadi $0,355>0,05$. Maka dapat di simpulkan bahwa data sampel minat belajar ada hubungan yang linear. 
b. Motivasi belajar dengan Hasil belajar fisika

Pada hasil pengujian statistik di bawah ini, dapat dilihat uji linearitas regresi adalah pada bagian Deviation from Linearity.

Tabel 10. Uji Linieritas Motivasi dan Hasil Belajar

\begin{tabular}{|c|c|c|c|c|c|c|c|}
\hline & & & $\begin{array}{l}\text { Sum of } \\
\text { Squares }\end{array}$ & Df & $\begin{array}{l}\text { Mean } \\
\text { Square }\end{array}$ & $\mathrm{F}$ & Sig. \\
\hline \multirow{5}{*}{$\begin{array}{l}\text { Hasil belajar * } \\
\text { Motivasi } \\
\text { Belajar }\end{array}$} & \multirow{3}{*}{$\begin{array}{l}\text { Between } \\
\text { Groups }\end{array}$} & (Combined) & 50,838 & 15 & 3,389 & 1,338 & ,271 \\
\hline & & Linearity & 29,547 & 1 & 29,547 & $\begin{array}{r}11,66 \\
3\end{array}$ & 003 \\
\hline & & $\begin{array}{l}\text { Deviation } \\
\text { from Linearity }\end{array}$ & 21,291 & 14 & 1,521 & 600 & ,833 \\
\hline & \multicolumn{2}{|c|}{ Within Groups } & 48,133 & 19 & 2,533 & & \\
\hline & \multicolumn{2}{|l|}{ Total } & 98,971 & 34 & & & \\
\hline
\end{tabular}

Berdasarkan tabel 10 di atas,di peroleh nilai signifikansisebesar 0,833 dengan taraf signifikansi $\alpha=0,05$, jadi $0,833>0,05$. Maka dapat di simpulkan bahwa data sampel motivasi belajar ada hubungan yang linear.

\section{Pengujian Hipotesis}

a. Hubungan antara minat belajar terhadap hasil belajar fisika:

Pada hasil pengujian statistik memperlihatkan kekuatan hubungan atau besar kontribusi dilihat pada Tabel 11.

Tabel 11. Uji Korelasi Minat dan Hasil Belajar

\begin{tabular}{lccc} 
Model & $\mathrm{R}$ & $\mathrm{R}$ Square & Sig. F Change \\
\hline 1 &, $609^{\mathrm{a}}$ &, 371 &, 000 \\
\hline
\end{tabular}

Berdasarkan tabel 4.9 di atas, menunjukkan korelasi besarnya 0,609 dan $R^{2}$ besarnya 0,371 . Koefisien korelasi tersebut signifikan karena nilai signifikansi 0,000, jauh lebih kecil dari taraf signifikansi $\alpha$ yang ditetapkan, yakni 0,05. Jadi dapat disimpulkan bahwa $\mathrm{Ha}_{1}$ di terima atau terdapat hubungan yang signifikan antara minat belajar terhadap hasil belajar fisika. Berdasarkan rumus koefesien determinasi: $\mathrm{KP}=\mathrm{r}^{2} \mathrm{x} 100 \%$, maka diperoleh $0,371 \times 100 \%$. Jadi kontribusi variabel minat belajar terhadap variabel hasil belajar fisika besarnya $37,1 \%$.

\section{b. Hubungan antara motivasi belajar terhadap hasil belajar fisika}

Pada hasil pengujian statistik memperlihatkan kekuatan hubungan atau besar kontribusi dilihat pada Tabel 12 . 
Tabel 12. Uji Korelasi Motivasi dan Hasil Belajar

\begin{tabular}{cc|c|c} 
Model & $\mathrm{R}$ & R Square & Sig. F Change \\
\hline 1 &, $546^{\mathrm{a}}$ &, 299 &, 001 \\
\hline
\end{tabular}

Berdasarkan tabel 12 di atas, menunjukkan nilai korelasi besarnya 0,546 dan $R^{2}$ besarnya 0,299 . Koefisien korelasi tersebut signifikan karena nilai signifikansi 0,001 , jauh lebih kecil dari taraf signfikansi $\alpha$ yang ditetapkan, yakni 0,05. Jadi dapat disimpulkan bahwa $\mathrm{Ha}_{2}$ di terima atau terdapat hubungan yang signifikan antara motivasi belajar terhadap hasil belajar fisika. Kontribusi variabel motivasi belajar terhadap hasil belajar fisika besarnya 29,9\%.

Berdasarkan hasil penelitian dan data yang diperoleh, serta berdasarkan kisi-kisi pada angket minat belajar yakni pada indikator Perasaan senang, banyak siswa yang memberikan pendapat positif tentang pembelajaran fisika. Hal tersebut juga didukung oleh (Susanto:2016:57) yang berpendapat bahwa minat adalah suatu kesukaan, kegemaran atau kesenangan akan sesuatu. Setelah semua data pada minat belajar dilakukan pengujian statistik, maka di peroleh hasil yang menunjukan bahwa korelasi besarnya 0,609 dan $R^{2}$ besarnya 0,371 . Koefisien korelasi tersebut signifikan karena nilai signifikansi 0,000 , jauh lebih kecil dari taraf signifikansi $\alpha$ yang ditetapkan, yakni 0,05 . Berdasarkan rumus koefesien determinasi: $\mathrm{KP}=$ $\mathrm{r}^{2} \mathrm{x} 100 \%$, maka di peroleh $0,371 \times 100 \%$. Jadi kontribusi variabel minat belajar terhadap variabel hasil belajar fisika besarnya 37,1\%. Dengan demikian ada hubungan yang signifikan antara minat belajar terhadap hasil belajar fisika. Hal ini sejalan dengan penelitian yang di lakukan oleh Siwi Puji Astuti pada tahun 2015, dengan judul "Pengaruh kemampuan awal dan Minat Belajar terhadap Prestasi Belajar Fisika" yang menunjukan bahwa (1) terdapat pengaruh kemampuan awal dan minat secara bersama-sama terhadap presentasi belajar fisika (2) terdapat pengaruh kemampuan awal terhadap prestasi belajar fisika (3) terdapat pengaruh minat belajar terhadap prestasi belajar fisika. Nadzifah Ajeng Daniyati dan Sugiman pada tahun 2015 Vol. 10 No.1. penelitian ini meneliti "Hubungan antara kemampuan verbal, kemampuan interpersonal, dan Minat Belajar dengan Prestasi Belajar matematika" yang menunjukan bahwa Hubungan antara kemampuan verbal dan prestasi belajar matematika dengan kontribusi sebesar 23,62\%; hubungan antara kemampuan interpersonal dan prestasi belajar matematika dengan kontribusi sebesar $1,64 \%$ dan hubungan antara minat belajar matematika dan prestasi belajar matematika dengan kontibusi sebesar $6,15 \%$.

Berdasarkan hasil penelitian dan data yang di peroleh, serta berdasarkan kisi-kisi pada angket motivasi belajar yakni pada indikator Adanya hasrat dan keinginan berhasil, banyak siswa yang memberikan pendapat positif. Hal tersebut juga didukung oleh Uno dalam Tony (2016:25-27) yang berpendapat bahwa siswa yang memiliki hasrat ingin berhasil akan mengerjakan tugas dari guru dengan baik, menyelesaikan tugas dari guru, bertanya saat menemukan kesulitan dan menyiapkan waktu khusus untuk dapat mengerjakan pekerjaan di rumah. Setelah semua data pada motivasi belajar di lakukan pengujian statistik, maka di peroleh hasil yang menunjukan bahwa korelasi $\mathrm{R}$ besarnya 0,546 dan $R^{2}$ besarnya 0,299. Koefisien korelasi tersebut signifikan karena nilai signifikansi 0,001, jauh lebih kecil dari taraf signfikansi $\alpha$ yang ditetapkan, yakni 0,05 . Berdasarkan rumus koefesien determinasi: $\mathrm{KP}=\mathrm{r}^{2} \mathrm{x} 100 \%$, maka di peroleh $0,299 \times 100 \%$. Jadi kontribusi variabel motivasi belajar terhadap hasil belajar fisika besarnya $29,9 \%$. Dengan demikian maka ada hubungan yang signifikan antara motivasi belajar terhadap 
hasil belajar fisika. Hal ini sejalan dengan penelitian yang di lakukan oleh Ilyas, yang berjudul "Hubungan kecerdsan Emosional dan Motivasi Belajar fisika dengan Hasil belajar fisika peserta didik di SMA Negeri 1 Tinggi Moncong" yang menunjukan bahwa Terdapat hubungan yang signifikan antara Motivasi Belajar fisika dengan Hasil belajar fisika peserta didik di SMA Negeri 1 Tinggi Moncong. Aminah Ekawati tahun 2014 yang berjudul "Pengaruh Motivasi dan Minat terhadap Hasil Belajar Matematika kelas VII SMPN 13 Banjarmasin" yang menunjukan bahwa minat belajar berpengaruh positif terhadap hasil belajar siswa.

\section{Simpulan}

Berdasarkan pada hasil penelitian dapat disimpulkan bahwa terdapat hubungan yang signifikan antara minat belajar terhadap hasil belajar fisika kelas X SMA Negeri 1 Wewewa Selatan. Hal ini dapat dibuktikan dengan nilai $\mathrm{x}=0,609$ yang jika di bandingkan dengan $\mathrm{x}=0,3246$, dan juga jika di lihat dari

nilai signifikansinya $0,000<0,05$. Terdapat hubungan yang signifikan antara motivasi belajar terhadap hasil belajar fisika kelas X SMA Negeri 1 Wewewa Selatan. Hal ini dapat di buktikan dengan nilai $\mathrm{x}=0,546$ di bandingkan dengan $\mathrm{x}=0,3246$, dan juga jika di lihat dari nilai signifikansinya $0,001<0,05$.

\section{Referensi}

A.M, S. (2016). Interaksi dan Motivasi Belajar Mengajar. Jakarta: PT: Raja Grafindo Persada.

Astuti,Siwi Puji (2015). Pengaruh Kemampuan Awal dan Minat Belajar Terhadap Prestasi Belajar Fisika. Jurnal Formatif, 5(1).

Daniyati, N. A. (2015). Hubungan Antara Kemampuan Verbal, Kemampuan Interpersonal, dan Minat Belajar dengan Prestasi Belajar Matematika. Pythagoras: Jurnal Pendidikan Matematika, 10(1), 50-60. https://doi.org/10.21831/pg.v10i1.9109

Djamarah, S. B. (2016). Psikologi Belajar. Jakarta: Rineka Cipta.

Ekawati, A. (2014). Pengaruh Motivasi dan minat terhadap hasil belajar matematika kelas VII SMPN 13 Banjar Masin. Lentera, Jurnal Ilmiah Kependidikan , 1-10.

Ilyas. (2014). Hubungan Kecerdasan Emosional Dan Motivasi Belajar Fisika Dengan Hasil Belajar Fisika Peserta Didik Kelas X Sma Negeri 1 Tinggimoncong. Pascasarjana UNM. 3, 27-32.

Majid, A. (2011). Perencanaan Pembelajaran. Bandung: Remaja Rosdakarya.

Margono. (2007). Metodologi Penelitian Pendidikan. Jakarta: Rineka Cipta.

Riduwan. 2010. Skala Pengukuran variabel-variabel Penelitian. Bandung: Alfabeta.

Rusman. (2012). Model-Model Pembelajaran. Jakarta: Raja Gravindo Persada.

Slameto. (2010). Belajar dan Faktor yang mempengaruhinya. Jakarta: Rineka Cipta.

Sudjana, N. (2009). Penilaian Hasil Belajar Mengajar. Bandung: PT. Remaja Rosdakarya. 
Susanto, A. (2016). Teori Belajar dan Pembelajaran. Jakarta: Prenada Media Group.

Syarif, M. (2016). Strategi Pembelajaran. Jakarta: Raja Grafindo Persada.

Uno, H. B. (2016). Teori Motivasi dan Pengukurannya Analisis di Bidang Pendidikan. Jakarta: PT. Bumi Aksara. 